\title{
Sintering Behavior and Interfacial Analysis of Ni/Cu Electrode with $\mathrm{BaTiO}_{3}$ Particulates
}

\author{
CHIH-LUNG CHEN, ${ }^{1}$ WEN- HSI LEE ${ }^{2} \&$ WEN-CHENG J. WEI ${ }^{1, *}$ \\ ${ }^{1}$ Institute of Mat's Sci. \& Eng., National Taiwan University, Taipei, Taiwan 106, Republic of China \\ ${ }^{2}$ Phycomp Taiwan Ltd., P.O. Box 35-106, Kaohsiung, Taiwan, Republic of China
}

Submitted September 1, 2003; Revised March 1, 2004; Accepted March 9, 2004

\begin{abstract}
The sintering behavior of $\mathrm{Ni}$ electrode alloyed with $\mathrm{Cu}$ and the interfacial structure between $\mathrm{Ni} / \mathrm{Cu}$ to $\mathrm{BaTiO}_{3}$ (BT) have been investigated. The quantitative properties, which include thermal shrinkage, thermal expansion, wetting behaviors of $\mathrm{Ni} / \mathrm{Cu}$ alloys on $\mathrm{BT}$ sheet, and composition distribution were measured by several thermal analysis techniques (TGA/DTA/TMA) and microstructural techniques (SEM/TEM/ HRTEM) with energydispersive spectroscopy (EDS). The shrinkage of the $\mathrm{Ni} / \mathrm{Cu} / \mathrm{BaTiO}_{3}$ composite tested in $5 \% \mathrm{H}_{2} / \mathrm{N}_{2}$ atmosphere showed strong influence by the addition of $\mathrm{Cu}$, and retarded slightly due to the addition of the $\mathrm{BT}$ particulates. The $\mathrm{Cu}$ alloyed with $\mathrm{Ni}$ improves the continuity of the electrode and does not trigger mutual reaction between $\mathrm{Ni}$ and BT.
\end{abstract}

Keywords: $\mathrm{Ni}, \mathrm{Cu}, \mathrm{BaTiO}_{3}$, electrode, interfacial reaction

\section{Introduction}

In order to keep pace up with the trend in the miniaturization of electronic components, concentrated effort has been put in forced on the development of small multilayer ceramic capacitors (MLCCs) to meet the rapid development of integrated circuit and surface mounting technology. The demand of the MLCCs in high quality has quickly increased in the past decade. However, the high sintering temperature of $\mathrm{BaTiO}_{3}$ (BT) suggested the adoption of high melting point internal electrodes, such as $\mathrm{Pd}$ and $\mathrm{Ag} / \mathrm{Pd}$ alloy. To confront the requirements on smaller size, higher performance and lower cost, the manufacturing techniques of the MLCCs have closely engaged the development of base metal internal electrode (BME) and thinner dielectric ceramic layers [1-6]. Therefore, the fabrication of MLCCs lately has concentrated on the sintering process of BME and on the adjustment of dielectric ceramic composition, which are considered as the solutions of above critical issues $[5,7]$.

*To whom all correspondence should be addressed. E-mail: wjwei@ntu.edu.tw
Another challenging issue in manufacturing $\mathrm{Ni}$ based MLCCs is cofiring the electrode/dielectric multilayer structure. Many essential issues in cofiring technology of multilayer films include not only the formation mechanism of interfacial defects, but also the modification of the mismatch of sintering shrinkage. Whereas the different sintering kinetics and mechanisms between the Ni electrode and BT dielectrics are monitored, various types of cofiring defects, including cracks, delamination, and warpage come into important issues [3-9]. Those defects are often observed in the final products. In addition to those defects, silver migration form inner electrode into ceramics in the cofiring process of MLCCs is another critical factor, which affects the reliability and dielectric characteristics $[9,10]$. Moreover, the influence of carbon residue in the capacitor is also concerned. The residual carbon could increase the dielectric constant if the organics or polymer in the electrode couldn't be burned-out completely [11]. However, the investigation on the wetting and sintering behaviors of carbon with $\mathrm{BaTiO}_{3}$ couldn't be found in literature.

Metal-ceramic multilayers are prone to failure owing to the difference in the thermal expansion 
coefficient. Besides, a difference in the sintering rates between the metal electrode and the ceramic dielectric layers, consequently, the thermal mismatch problem has been recognized in the past reports [11, 12]. A basic understanding of the process resulting in these defects is needed to optimize the processing parameters and material compositions that minimize the formation of the defects and thus increase the production yield.

Several reports [13, 14] of MLCCs have focused on making a thinner dielectric layer, since capacitance per unit volume is approximately inversely proportional to the square of the thickness. However, the interfacial reaction of electrode (metal) elements into the dielectrics (ceramic) on the electrical properties of MLCCs will be more critical with decreasing the thickness of dielectric layer [15]. On the other hand, some technological difficulties have been experienced, such as delaminating of layer structure and discontinuity of the inner electrode of MLCCs. A multi-layer structure cofired metal-containing electrodes with BT may appear interdiffusion between BT and metal layer [16, 17]. It is not desirable because of the reduction of breakdown voltage and dielectric quality.

$\mathrm{Cu}$ as the second metallic additive is selected as a potential alloying phase to $\mathrm{Ni}[18,19]$. The crystalline structure of $\mathrm{Cu}$ is face-centered cubic (FCC), which is the same as the structure of $\mathrm{Ni}$. However, the $\mathrm{Cu}$ has an atomic radius just a few percents different to that of $\mathrm{Ni}$. Thermodynamically, the interfacial energy of Ni alloy system will be different from pure $\mathrm{Ni}$. $\mathrm{Cu}$ is a high electrical and thermal conductive material, and $\mathrm{Ni}$ is very good for corrosion resistance. For these reasons, a mixture of $\mathrm{Ni}$ and $\mathrm{Cu}$ is proposed for the use as the electrode of MLCCs [20]. Besides, BT is often added to the metal electrode so to reduce the coefficient mismatch of thermal expansion, and to increase the sintering match with BT dielectric layers. Most importantly, interfacial reaction may occur between the internal metal $(\mathrm{Ni} / \mathrm{Cu})$ electrode and dielectric ceramic layer.

One study about the reaction between $\mathrm{Cu}$ and $\mathrm{BaTiO}_{3}$ was reported by Richard et al. [21]. Two newly formed $\mathrm{Cu} / \mathrm{BaTiO}_{3}$ compounds, $\mathrm{Ba}_{8} \mathrm{Cu}_{2} \mathrm{Ti}_{22} \mathrm{O}_{54}$ and $\mathrm{Ba}_{4} \mathrm{Ti}_{13} \mathrm{O}_{30}$, were identified in a mixture of $\mathrm{BaCO}_{3}$, $\mathrm{CuO}$ and $\mathrm{TiO}_{2}\left(1: 1: 2\right.$ ratio) after sintered at $1380^{\circ} \mathrm{C}$ for $48 \mathrm{~h}$. The phase reflections were hardly found in the pattern of X-ray diffraction analysis. Interfacial reaction between BT to metallic electrodes was recognized to be an important role in the degradation of MLCCs [22]. In this study, the sintering behavior changing with the addition of $\mathrm{Cu}$ was investigated. The interfacial analysis
Table 1. Exact content of the $\mathrm{Ni} / \mathrm{Cu} / \mathrm{BT}$ composites tested in this study.

\begin{tabular}{llll}
\hline & \multicolumn{3}{c}{ Exact content of each phase (mass \%) } \\
\cline { 2 - 4 } Mark & Ni (\%) & BT $(\%)$ & $\mathrm{Cu}(\%)$ \\
\hline N15B & 85 & 15 & 0 \\
N15B10C & 76.5 & 15 & 8.5 \\
N15B30C & 59.5 & 15 & 25.5 \\
N30B30C & 49 & 30 & 21 \\
N60B30C & 28 & 60 & 12 \\
\hline
\end{tabular}

of $\mathrm{Ni} / \mathrm{Cu}$ with dielectric ceramic layer is also carefully characterized in order to clarify the role of $\mathrm{Cu}$.

\section{Experimental Procedures}

\subsection{Sample Preparation}

The original $\mathrm{BaTiO}_{3}$ powder (grade $\mathrm{PR}, \mathrm{Ba} / \mathrm{Ti}=$ 0.995, Degussa Uden, Japan) in average particle size of $0.67 \mu \mathrm{m}$ was used for the preparation of the plates in diameter of $5 \mathrm{~mm}$ and thickness of $3 \mathrm{~mm}$. The BT samples were calcined and sintered at $1200^{\circ} \mathrm{C}$ in air. Besides, two kinds of metallic powders were studied, including $\mathrm{Ni}(99.0 \%$, median particle size is $0.3 \mu \mathrm{m})$ and $\mathrm{Cu}(99.0 \%$, median particle size is $0.6 \mu \mathrm{m})$ supplied by Phycomp Co., Taiwan). The $\mathrm{Ni}$ and $\mathrm{Cu}$ can also be a form of paste in the solid content of either 71.2 mass $\%$ or 85.0 mass\%.

BT ceramic tape with inner electrodes was also made by tape-casting for the multilayer specimens. In the following section, the abbreviations, N, B and C mean the $\mathrm{Ni}, \mathrm{BaTiO}_{3}$ and $\mathrm{Cu}$ phases, respectively. The number in front of the abbreviation is the content of the material in mass \%, e.g. N20B representing Ni with 20 mass $\% \mathrm{BaTiO}_{3}$ phase. The exact composition of the composites is shown in Table 1.

\subsection{Analyses of Phases, Composition and Microstructure}

The phases of sintered bulks were identified by an X-ray diffractometer (Philips PW1710, Philips Co., Netherlands). The composition analysis of impurities in the raw powder was analyzed by the OxygenNitrogen and Carbon-Sulfur gaseous analyzers (LECO CS-136 and CS-244, LECO Co., USA). The morphologies of the polished and cross-section surfaces 
of $\mathrm{Ni} / \mathrm{Cu} / \mathrm{BaTiO}_{3}$ composites were analyzed by scanning electron microscopy (SEM, Philips XL30, Philips Co., USA) equipped with an X-ray energy dispersive spectroscopy (EDS, DX-4, EDAX Co., USA), and field-emission SEM (Leo Instrument 1530, England). Thin foil samples for TEM observation were cut to thin layers by Isomet (Buehler Ltd., USA), then was ground and reduced to $<50 \mu \mathrm{m}$ by using Minimet grinder (Buehler Ltd., USA). Afterward, the sample was milled by an ion miller (PIPS, Gatan Co., USA) until a thin perforated sample was obtained. Transmission electron microscopes (TEM, 100CXII, JEOL Co., Jpn. or FETEM, Tecnai 300 kV, Philips, Netherlands) equipped with EDS were employed to analyze the microstructure and composition distribution near the interfaces.

\subsection{Thermal and Shrinkage Analysis}

The sintering behavior of the $\mathrm{Ni} / \mathrm{Cu} / \mathrm{BT}$ composites was analyzed by using a thermal mechanical analyzer (TMA, SETSYS TMA16/18, SETRAM Co., France), which could operate to $1700^{\circ} \mathrm{C}$. The linear expansion or shrinkage of these specimens was detected. Besides, TGA test was also conducted (Thermal Analyst 2000, Dupont Co., USA). About $10 \mathrm{mg}$ of sample was placed in $\mathrm{Al}_{2} \mathrm{O}_{3}$ crucible in each test. Laminated samples before the thermal tests were always going through a suitable binder-burn-out (BBO) step.

\section{Results and Discussion}

\subsection{Dilatometric Behavior of Ni with BT}

The effects of BT on the sintering of $\mathrm{Ni}$ are reported in Fig. 1(a). The submicron Ni powder starts to densify as low as $500^{\circ} \mathrm{C}$. As 5-20 mass\% of BT powder is added, the threshold of sintering shifts to higher temperature. It is conspicuous that the densification of the pure Ni paste is almost complete before the temperature reaches the densification of pure BT powder compact. In addition, the Ni with BT powder shows a linear shrinkage of 15.5 to $17.0 \%$ when sintered at $1300^{\circ} \mathrm{C}$. The shrinkage is nearly $5 \%$ more than that of a pure Ni due to different packing efficiency of $\mathrm{Ni}$ to the binary $\mathrm{Ni} / \mathrm{BT}$ powder systems.

The sintering behavior of the $\mathrm{Ni}$ is slightly altered by the addition of BT. The threshold sintering temperature

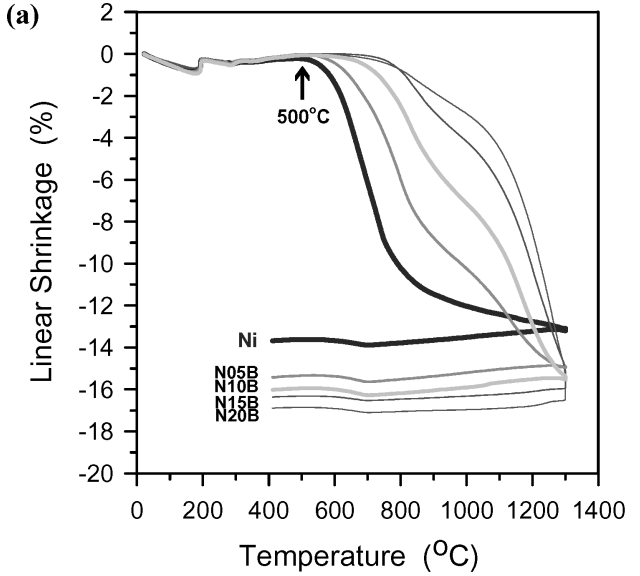

(b)



Fig. 1. (a) Dilatometric sintering curves showing the shrinkage behavior of Ni sintered with various amounts of BT at a rate of $10^{\circ} \mathrm{C} / \mathrm{min}$ to $1300^{\circ} \mathrm{C}$, and held for $10 \mathrm{~min}$ in $5 \% \mathrm{H}_{2} / \mathrm{N}_{2}$ atmosphere, (b) the shrinkage properties of $\mathrm{Ni}$ with $\mathrm{BT}$ as a function of BT content.

(onset of sintering) is varied gradually. The addition of BT powders retards the shrinkage of the Ni electrode, leading to better interfacial matching. The results of the shrinkage and threshold temperature of each Ni/BT sample are summarized in Fig. 1(b). It is also noted that the shrinkage curves of the Ni/BT composites holding at $1300^{\circ} \mathrm{C}$ depict $2-4 \%$ additional shrinkage (a straight line), which might imply a liquid phase sintering. The phenomena will be investigated in the later section.

Figure 2 indicates the microstructure of layer, either pure Ni or N15B, between BT dielectric layers. The flaws are found at the interface. That is the lack of a good physical match between the layers resulted from inferior interfacial bonding (or called "de-bonding"). This kind of interfacial condition at the interface is 

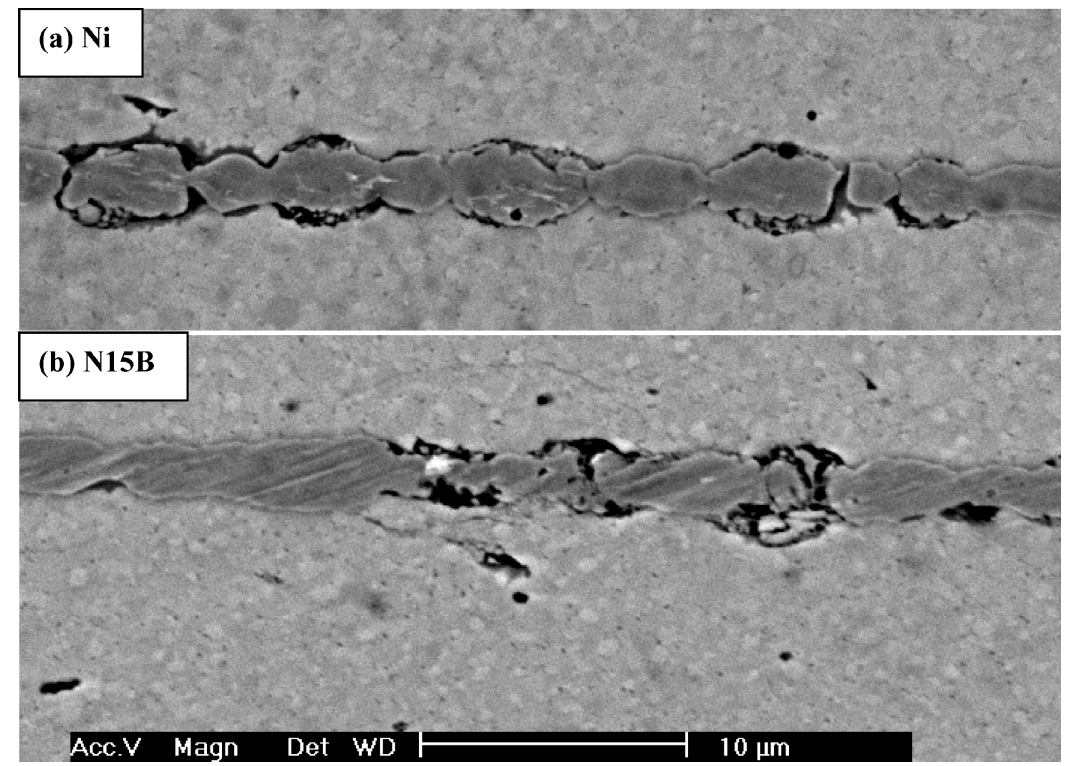

Fig. 2. SEM micrographs between BT ceramics and electrode layer of (a) pure Ni; and (b) 15 mass\% BT-doped Ni. The samples were sintered at $1250^{\circ} \mathrm{C}$ for $1 \mathrm{~h}$ in $5 \% \mathrm{H}_{2} / \mathrm{N}_{2}$ atmosphere.

easily damaged, so to cause the interfacial delamination. Compared to N15B, the electrode layer hardly shows improvement on the bonding conditions, as shown in Fig. 2(b). Besides, the continuity of the metal electrode is still poor. A good adhesion mechanism between electrode layer and BT ceramics should be active unless the interface of thin electrode/BT layers always shows the defects. In the next section, the discontinuity of the electrode will be shown greatly improved by the addition of $\mathrm{Cu}$.

\subsection{Thermal Behavior of Ni/BT with $\mathrm{Cu}$}

A series of TGA and TMA tests of NBC composite samples was conducted in reducing atmospheres. The humidity in the flowing gas was pre-determined. The dew-point was $-63^{\circ} \mathrm{C}$, which corresponds to a $\mathrm{H}_{2} \mathrm{O}$ content of $7 \mathrm{ppm}$, or an oxygen partial pressure of $\mathrm{P}_{\mathrm{O} 2} \sim 5 \times 10^{-11} \mathrm{~atm}$. The result indicated that the sintering condition in $5 \% \mathrm{H}_{2} / \mathrm{N}_{2}$ might provide an appropriate reducing atmosphere protecting the metal phase from oxidation.

TGA tests of the samples with and without $\mathrm{Cu}$ were conducted. The results are shown in Figs. 3(a) and (b), illustrating that the oxidation behavior of the dry pastes depends on the content of the $\mathrm{Cu}$ and the atmosphere.
The mass gain of $\mathrm{N} 15 \mathrm{~B}$ sample occurs at $\geq 360^{\circ} \mathrm{C}$ implying the oxidation of $\mathrm{Ni}$. In comparison, the oxidation curve of N15B20C shows more mass gain (Fig. 3(a)) and occurs from $250^{\circ} \mathrm{C}$. The occurrence of additional mass gain (ca. $2 \%$ ) is due to the oxidation of $\mathrm{Cu}$.

Figure 3(b) shows the TGA tests in reducing atmosphere. The mass-change curves of N15B and N15B10C show a small reduction taking place from 250 and $290^{\circ} \mathrm{C}$, respectively. The amount of mass loss $(0.3 \%$ or $0.6 \%)$ is proportional to the amount of $\mathrm{Cu}$ addition. Most importantly, the reduction of the $\mathrm{Cu}$ oxides is responsible form the mass reduction carried out in a dried $5 \% \mathrm{H}_{2} / \mathrm{N}_{2}$ up to $310^{\circ} \mathrm{C}$. Nevertheless, the mass gain of $\mathrm{Ni} / \mathrm{Cu} / \mathrm{BT}$ above $300^{\circ} \mathrm{C}$ of $\mathrm{TGA}$ result (Fig. 3) is possibly either the oxidation of copper or a background drifting of the TGA. However, based on the XRD analysis of the calcined samples, it depicted that only a single FCC phase appeared. No crystalline $\mathrm{Ni}$ - or $\mathrm{Cu}$-oxides are detected. That means native oxide scale in amorphous condition could exist on the $\mathrm{Cu}$ powder (or bulk) surface.

\subsection{Effect of $\mathrm{Cu}$ on Sintering of $\mathrm{Ni}-\mathrm{BT}$}

Various amounts of $\mathrm{Cu}$ were added in the N15B bulk in order to investigate the densification behavior of 
(a)

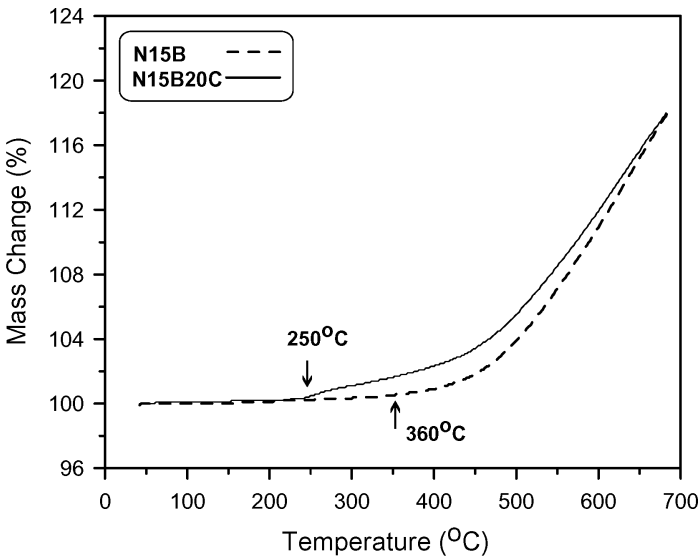

(b)



Fig. 3. TGA results of dried paste N15B (after BBO) with various contents of $\mathrm{Cu}$. The testing conditions are $5^{\circ} \mathrm{C} / \mathrm{min}$ (a) in air (b) in flowing $5 \% \mathrm{H}_{2} / \mathrm{N}_{2}$ atmosphere.

the electrode material. The amount of BT is fixed to 15 mass\%. The dilatometric data are shown in Fig. 4, in which the curves can be categorized into two groups. One is the samples that contain less than 30 mass $\% \mathrm{Cu}$. The other is more than 30 mass $\% \mathrm{Cu}$.

Samples in the first-group (Fig. 4(a)) start sintering at $800^{\circ} \mathrm{C}$, and undergo faster shrinkage above $1080^{\circ} \mathrm{C}$. It is concerned that the $\mathrm{Cu}$ may melt near $1080^{\circ} \mathrm{C}$ and will quickly alloy with $\mathrm{Ni}$. That, especially the $\mathrm{N} 15 \mathrm{~B} 30 \mathrm{C}$, may result in a small volume expansion in the range from 1080 to $1200^{\circ} \mathrm{C}$. The amount of expansion gets more apparent, even higher than $1200^{\circ} \mathrm{C}$ as the $\mathrm{Cu}$ content is $\geq 30 \%$. Every sample of low $\mathrm{Cu}$-content ( $\geq 20 \%$ ) shows similar sintering threshold temperatures between $700-800^{\circ} \mathrm{C}$, and a rapid rate of shrinkage above $1100^{\circ} \mathrm{C}$. A shrinkage phenomenon takes place as the sintering temperature holding at $1300^{\circ} \mathrm{C}$ for $60 \mathrm{~min}$ (Fig. 4(a)). (a)

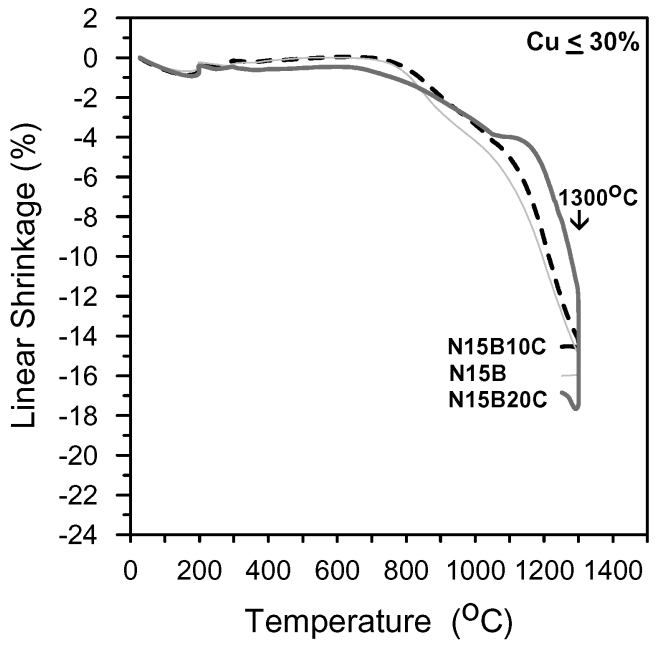

(b)



Fig. 4. Dilatometric sintering curves of $\mathrm{Ni} / \mathrm{BT} / \mathrm{Cu}$ composites sintered to (a) $1300^{\circ} \mathrm{C}$, and (b) $1200^{\circ} \mathrm{C}$, then held for $10 \mathrm{~min}$ in $5 \% \mathrm{H}_{2} / \mathrm{N}_{2}$ atmosphere.

The second-group samples (Fig. 4(b)) show a different shrinkage behavior from the samples in the firstgroup. First of all, small amount (1\%) of the shrinkage in the second-group samples was measured in the temperature range from 300 to $450^{\circ} \mathrm{C}$, which might be the reduction of $\mathrm{Cu}$-oxide. The surface of the submicron $\mathrm{Cu}$ particle in the original metal paste is likely in an oxidized condition. During the reduction of $\mathrm{CuO}$ in $5 \% \mathrm{H}_{2} / \mathrm{N}_{2}$, the sample experiences volume shrinkage as below.

$$
\mathrm{CuO} \rightarrow \mathrm{Cu}, \quad \Delta \mathrm{V}=-44 \%
$$

Therefore, the more the $\mathrm{Cu}$ content, the greater the shrinkage within the range of $300-450^{\circ} \mathrm{C}$. 


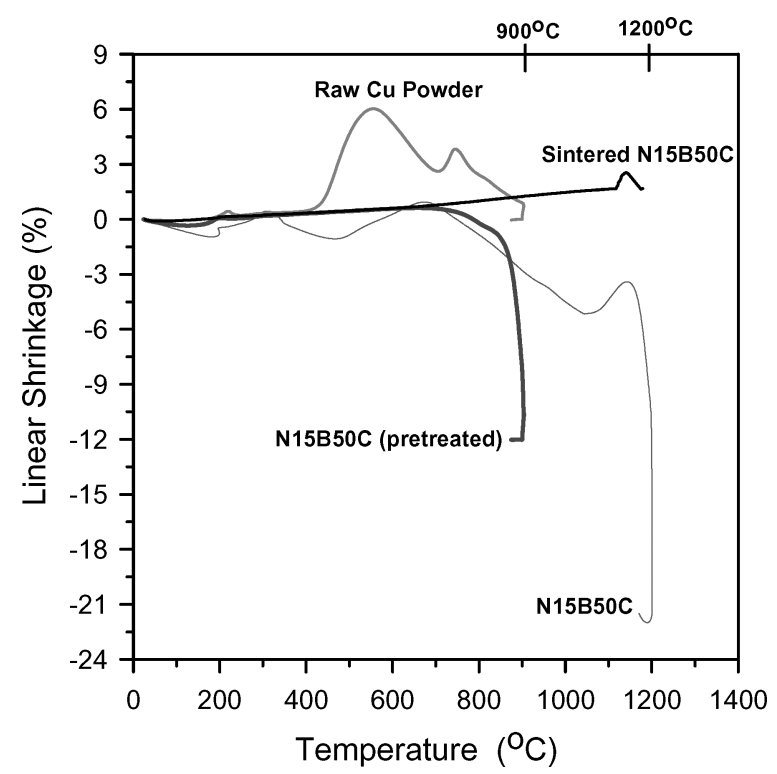

Fig. 5. Dilatometric sintering curves of pure $\mathrm{Cu}$ and several $\mathrm{N} 15 \mathrm{~B} 50 \mathrm{C}$ composites sintered or treated at various temperatures in $5 \% \mathrm{H}_{2} / \mathrm{N}_{2}$ atmosphere.

It's also noted that two expansions occur between 450 to $700^{\circ} \mathrm{C}$ and 1080 to $1200^{\circ} \mathrm{C}$, respectively. In order to investigate the reasons causing the expansions, we prepared two sets of samples for comparisons. The results of the sintering tests are shown in Fig. 5. The first set includes two samples, one is pure $\mathrm{Cu}$ compact made by die-pressing, and the other is pretreated $\mathrm{N} 15 \mathrm{~B} 50 \mathrm{C}$ which has been calcined at $900^{\circ} \mathrm{C}$ for $10 \mathrm{~min}$. The second set includes two samples as well, one is green N15B50C compact and the other N15B50C has been sintered at $1200^{\circ} \mathrm{C}$. That means that the organics (e.g. binder) in the paste or the impurity in $\mathrm{Cu}$ particles after $900^{\circ} \mathrm{C}$ or $1200^{\circ} \mathrm{C}$ treatment is cleaned from the sample. However, the states of $\mathrm{Ni}$ alloyed with $\mathrm{Cu}$ are also different after $1200^{\circ} \mathrm{C}$ treatment.

The result of first set sample clearly reveals the difference of the $\mathrm{Cu}$ powder compacts with calcinations, so to reveal the effects of any impurity in the raw $\mathrm{Cu}$ powder. The raw $\mathrm{Cu}$ powder had the impurity contents of O: $0.57 \%, \mathrm{~N}: 0.08 \%, \mathrm{C}: 0.51 \%$, and S: $0.004 \%$. It is apparent that the carbon content is high possibly due to polymeric residue coming from $\mathrm{Cu}$ paste. Of course, it is concerned that the raw $\mathrm{Cu}$ and N15B50C (which shows $\mathrm{C}$ content of $0.09 \%$ ) powders adsorbed carbonaceous residue on the particle surface. It is concerned that the carbon content may affect the wetting behavior of $\mathrm{Ni}$ (or $\mathrm{Ni} / \mathrm{Cu}$ ) electrode. In this case, the carbon content of N15B50C was analyzed to be $\leq 0.5 \%$. The amount of carbon residue was typical value in the $\mathrm{Ni} / \mathrm{BT}$ samples. It shouldn't be the critical factor to the sintering characteristics. But, the thermal expansion in the range from 450 to $700^{\circ} \mathrm{C}$ of both samples could be the results of evaporation of volatile gas $\left(\mathrm{CO}\right.$ or $\left.\mathrm{CO}_{2}\right)$. The concentration of carbonaceous gas is enough to result in the volume expansion of the $\mathrm{Ni} / \mathrm{Cu} / \mathrm{BT}$ composites above $450^{\circ} \mathrm{C}$. It is consistent to the curve of pretreated N15B50C in Fig. 5 that shows no shrinkage up to $700^{\circ} \mathrm{C}$. The expansion didn't occur in the pretreated N15B50C specimen, in which the $\mathrm{Cu}$ did not have any gaseous residue after the pre-treatment.

The second expansion starting from $1080^{\circ} \mathrm{C}$ in Fig. 4(b) can be the causes of $\mathrm{Cu}$ melting and/or alloying effect. Liquid phase formation is close relation to the melting of $\mathrm{Cu}\left(T_{m}=1065^{\circ} \mathrm{C}\right)$. This is why the N15B50C sample pre-sintered at $1200^{\circ} \mathrm{C}$ hardly shows any expansion, except an expansion aft ca. $1150^{\circ} \mathrm{C}$. That is the reason why the pre-sintered N15B50C does not show extensive linear shrinkage comparing to the original N15B50C which experiences $18 \%$ linear shrinkage at $1200^{\circ} \mathrm{C}$.

The final shrinkage of N15B30C and N15B40C are 10 and $11.7 \%$ at $1200^{\circ} \mathrm{C}$ for $1 \mathrm{~h}$, respectively. But the sample of N15B50C experiences a greater shrinkage possibly because the sintering temperature is close to the melting temperature of $\mathrm{Ni50Cu}$ alloy. The wetting of $\mathrm{Ni} / \mathrm{Cu}$ matrix on solid particles (BT) is more conspicuous during sintering. Therefore, the surface tension of the $\mathrm{Ni} / \mathrm{Cu}$ drives the particles together, resulting in the largest linear shrinkage ( 20\%) of N15B50C among the NBC specimens.

\subsection{Microstructural Continuity of $\mathrm{Ni} / \mathrm{Cu}$ Electrode}

The microstructures of various NBC composites sintered at $1300^{\circ} \mathrm{C}$ for $1 \mathrm{~h}$ in $5 \% \mathrm{H}_{2} / \mathrm{N}_{2}$ atmosphere are shown in Fig. 6. The Ni/Cu alloy appears darker contrast, and the BT particles are in white contrast due to the effects of different electric conductivities for each phase. Figure 6(a) shows that the BT particles form clusters in the Ni matrix. According to percolation threshold, the BT clusters are still isolated (lower than 16 vol\% inclusion). Besides, the average size of BT isolated particle is $1.43 \mu \mathrm{m}$ as shown in Fig. 6(a). The electric conductivity of the electrode (N15B) is still good as the Ni matrix is dense. However, the continuity 
(a)



(b)

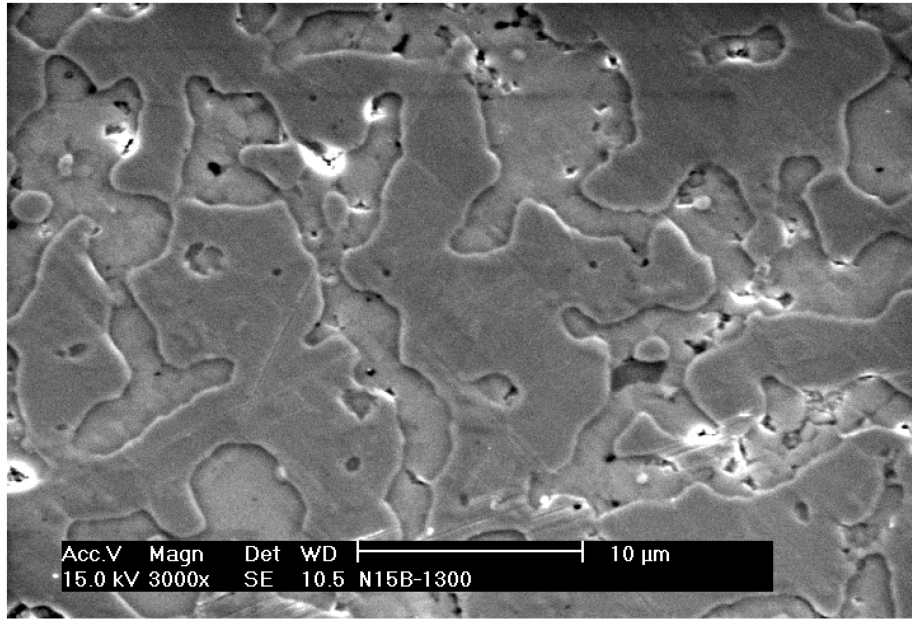

(c)



Fig. 6. SEM micrographs of the polished surfaces of (a) N15B, (b) N15B30C, and (c) N30B30C composites after sintered at $1300^{\circ} \mathrm{C}$ for $1 \mathrm{~h}$ in $5 \% \mathrm{H}_{2} / \mathrm{N}_{2}$ atmosphere. (a) and (b) were imaged by secondary electron (SE) mode, (c) is by back-scattering (BS) mode. 
of the electrode depend strongly on the wetting condition of Ni on BT. Figure 6(b) shows the N15B alloyed with 30 mass $\%$ of $\mathrm{Cu}$. The density of metal matrix of N15B30C composite is higher than the sintering condition of N15B composite in Fig. 6(a). The sintered N15B30C composite shows almost fully densification ( $\geq 99 \%$ T.D.) after this heat-treatment.

N15B30C composite shows a good wetting and the $\mathrm{Ni} / \mathrm{Cu}$ alloy apparently cover the BT particle surface with the Ni/Cu alloy. As the contents of BT increased to $30 \%$ in the matrix, e.g. the N30B30C in Fig. 6(c), the BT phase obviously dispersed in the matrix. No doubt the $30 \%$ BT clusters form continuous phase due to the content higher than percolation threshold (higher than $16 \mathrm{vol} \%$ ). Besides, the porosity of the N30B30C composite becomes more owing to unfinished sintering of BT particle cluster. Although BT particles were distributed in the mixture, they tended to coalesce as the increase of BT content. The effect of electrode surface area on dielectric constant will be also considered because of the additional surface area is formed in the $\mathrm{Ni} / \mathrm{Cu}$ electrode with BT particles. That is, too much $\mathrm{BT}$ addition might reduce the dielectric properties of MLCC due to the decrease of the conductive area in

(a)



(b)



Fig. 7. SEM micrographs of (a) N15B and (b) N15B50C layers sandwiched between BT plates, and sintered at $1250^{\circ} \mathrm{C}$ for $1 \mathrm{~h}$ in $5 \% \mathrm{H}_{2} / \mathrm{N}_{2}$ atmosphere. 
the $\mathrm{Ni} / \mathrm{Cu}$ electrode. We have to take the densification and electric properties of the electrode into account. Therefore, the optimal formulation, N15B30C, for the composite is proposed in this study.

Figure 7 is a set of SEM images of inner N15B electrode layers without and with $\mathrm{Cu}$ additive. The images show two important phenomena. One is the shape of pure Ni grains (Fig. 7(a)) which are nearly spherical, but irregular for N50C grains. Most of Ni particles shrink and result in the dewetting due to surface tension and become spherical at sintering temperature. The other is that the average Ni grain size of N50C is slightly larger than that of pure Ni grains. Obviously, the pure Ni layer has the weakest interface and poorly bonded with dielectric ceramic layer. Additionally, the evidences tell that the difference of interfacial energies of Ni on BT is larger than N50C on BT, which depicts good wetting and bonding in Fig. 7(b). We think that liquid-phase sintering of $\mathrm{Cu}$ in $\mathrm{Ni} / \mathrm{Cu}$ alloy may play an important rule during the sintering process. The images strongly suggest that the framework and structure of BT ceramics are improved by the rearrangement of the BT particles due to the wetting of $\mathrm{Ni} / \mathrm{Cu}$ alloy. Therefore, the continuity of the electrode would be enhanced by the addition of $\mathrm{Cu}$. But the melting of $\mathrm{Cu}$ is a transition state and show volume expansion observed from the TMA curves shown in Fig. 4.

\subsection{Interfacial Characteristics Between $\mathrm{Ni} / \mathrm{Cu}$ and $\mathrm{BT}$}

A detail analysis of previous N15B50C samples is shown in Fig. 8. The inclusions in the electrode layer are BT (as analyzed by EDS spectrum). The BT grains form isolated colonies in the electrode. The $\mathrm{Ni} / \mathrm{Cu}$ alloy shows a well solid-state mixing in the electrode. In addition to this, adverse interfacial reactions may degrade the electronic conductivity. The X-ray mapping images on the bottom of Fig. 8 appear a clear interface. No evidence of inter-diffusion between $\mathrm{Ba}$ and $\mathrm{Ni} / \mathrm{Cu}$ is observed.


Fig. 8. SEM and EDS (mapping) results of N15B50C electrode illustrating no obvious inter-diffusion between Ni/BT and $\mathrm{Cu} / \mathrm{BT}$ co-fired at $1250^{\circ} \mathrm{C}$ for $1 \mathrm{~h}$ in $5 \% \mathrm{H}_{2} / \mathrm{N}_{2}$ atmosphere. The partially agglomerated BT in the electrode layer causes some defects, including pores, fine cracks and discontinuity between metal layer and BT plates. 
(a)

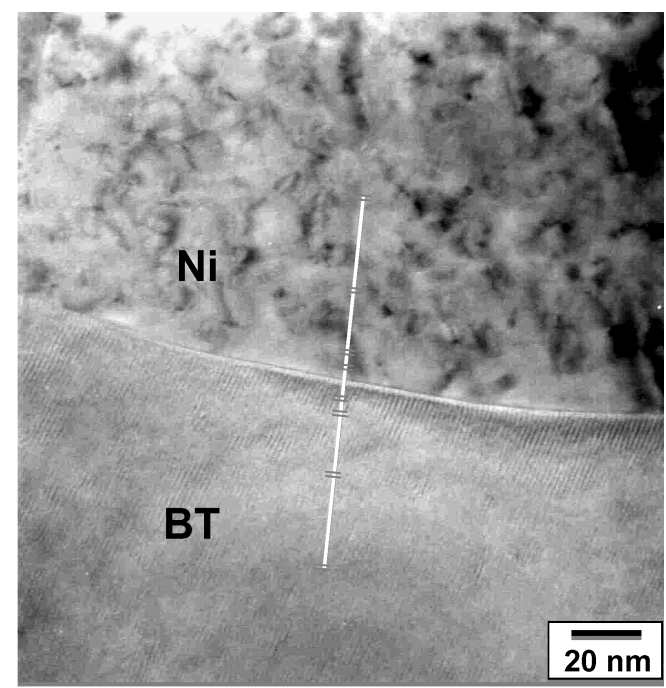

(b)

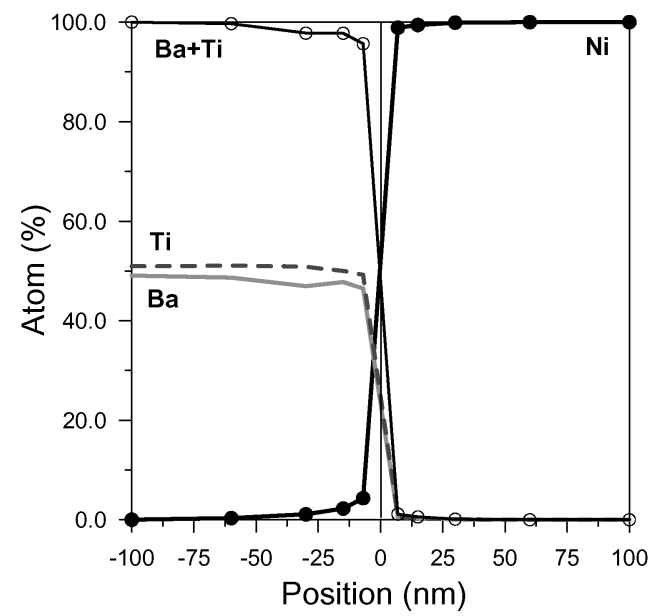

Fig. 9. (a) AEM micrograph of the $90 \% \mathrm{BT}-10 \% \mathrm{Ni}$ sintered at a rate of $10^{\circ} \mathrm{C} / \mathrm{min}$ to $1300^{\circ} \mathrm{C}$, held for $1 \mathrm{~h}$ in $5 \% \mathrm{H}_{2} / \mathrm{N}_{2}$ atmosphere, and (b) the qualitative composition analysis near the $\mathrm{BT} / \mathrm{Ni}$ interface.

Figure 9 also depicts the ceramic phase (BT inclusion) shows a brighter contrast and uniform distribution in the matrix. Composition analyses revealed that neither interdiffusion of elements nor interfacial reaction between the $\mathrm{Ni}$ and the BT phases occurred. The TEM/EDS results (Fig. 9(b)) appear the elaborate data for the interfacial behavior. The composition of BT and $\mathrm{Ni}$ is almost constant in each grain themselves. The interface between $\mathrm{Ni}$ and BT is clear, implying no inter-reaction occurred at the interface.

The solubility of $\mathrm{NiO}$ in $\mathrm{BaTiO}_{3}$ had not been precisely determined before. Some investigators [23-25] suggested that $\mathrm{Ni}$ ion would occupy $\mathrm{Ba}$ site because (a)

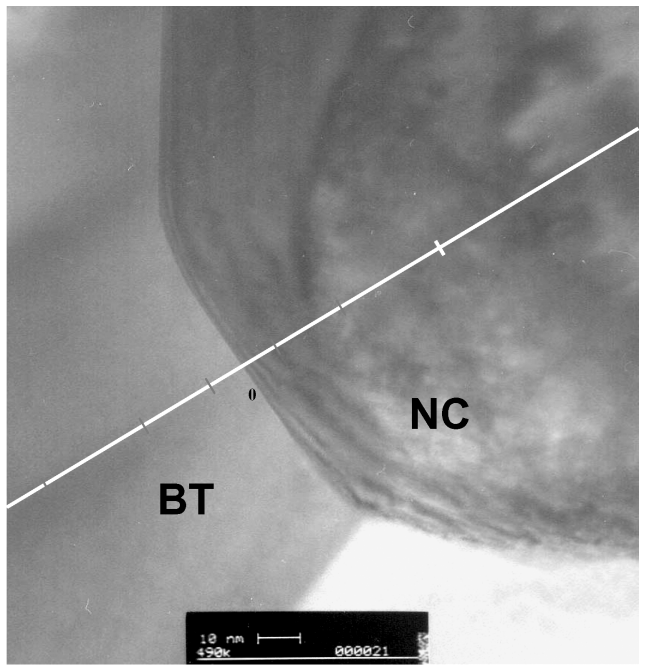

(b)

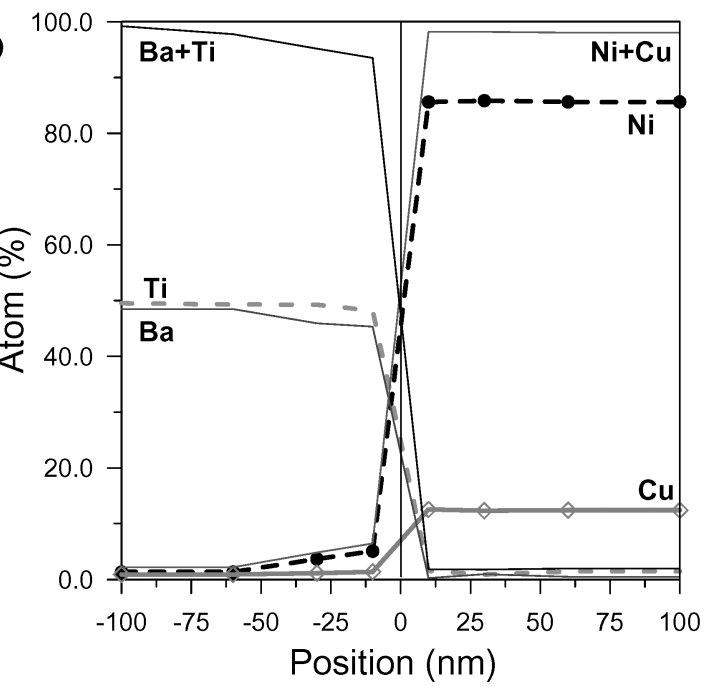

Fig. 10. (a) AEM micrograph of the $\mathrm{N} 15 \mathrm{~B} 10 \mathrm{C}$ sintered at $10^{\circ} \mathrm{C} / \mathrm{min}$ to $1300^{\circ} \mathrm{C}$ for $1 \mathrm{~h}$ at $5 \% \mathrm{H}_{2} / \mathrm{N}_{2}$ atmosphere, and (b) the qualitative composition analysis near the $\mathrm{BT} / \mathrm{Ni} / \mathrm{Cu}$ interface.

of the same valence state. The $\mathrm{Ba}$ site of $\mathrm{BaTiO}_{3}$ lattice replaced by $\mathrm{Ni}$ ion is still in dispute. However, low partial pressure of oxygen offered by $5 \% \mathrm{H}_{2} / \mathrm{N}_{2}$ is necessary to prevent the $\mathrm{Ni}$ from oxidation. Figure 10 also shown a clear interface between $\mathrm{BT}$ and the $\mathrm{Ni} / \mathrm{Cu}$ alloy imaged by AEM. No apparent defect, porosity, or reaction layers are found at the $\mathrm{BT} / \mathrm{NC}$ interface. The $\mathrm{Ni} / \mathrm{Cu}$ alloy shows a texture of metal phase. On the other hand, the detail EDS analysis is shown in Fig. 10(b). Herein the closest analysis point from the interface is in a distance of $10 \mathrm{~nm}$. The composition of $\mathrm{Ni} / \mathrm{Cu}$ atoms 


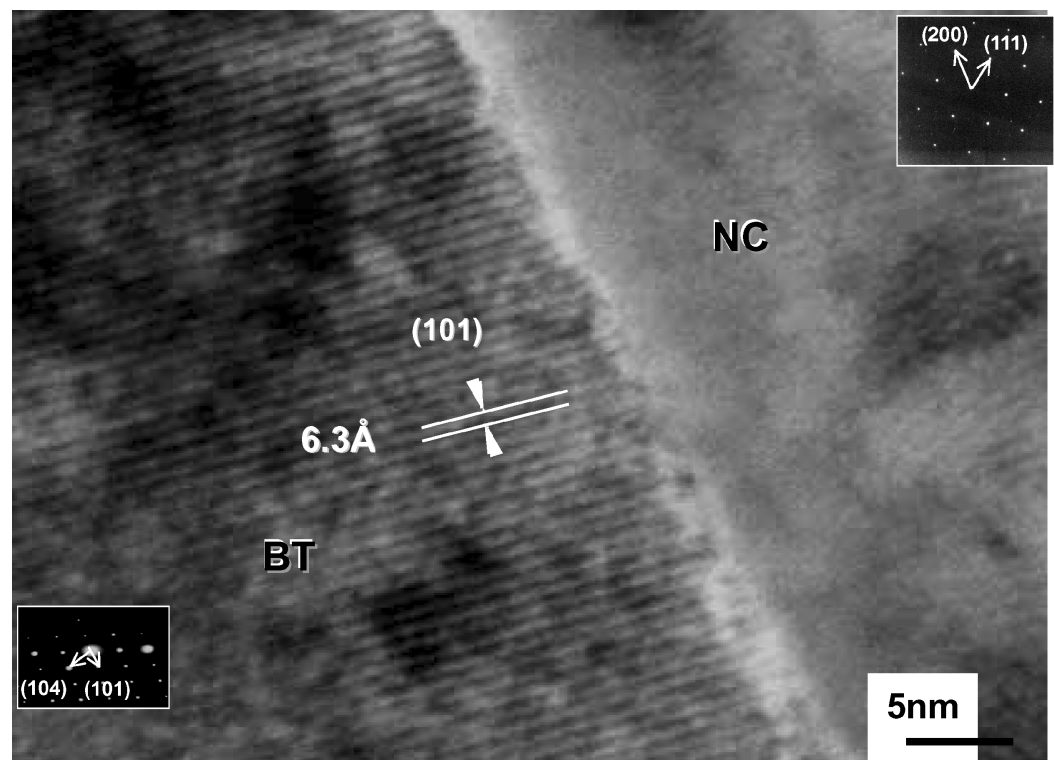

Fig. 11. TEM images between $\mathrm{Ni} / \mathrm{Cu}$ and $\mathrm{BT}$ interface in high resolution. The sample sintered at a rate of $10^{\circ} \mathrm{C} / \mathrm{min}$ to $1300^{\circ} \mathrm{C}$, held for $1 \mathrm{~h}$ in $5 \% \mathrm{H}_{2} / \mathrm{N}_{2}$ atmosphere.

abruptly reduces to nearly nothing across the interface. The residual $\mathrm{Ni} / \mathrm{Cu}$ intensity (3-10 at $\%$ ) found on the side of BT might imply almost no interfacial diffusion (or beam broadening).

A high-resolution TEM image of the interfacial structure between $\mathrm{BT}$ and $\mathrm{Ni} / \mathrm{Cu}$ measured immediately is presented in Fig. 11, indicating the clean and no defects including pores, crack, glassy phase and reaction layers at the interface. The diffraction patterns show both crystalline phases [030] zone pattern of BT phase, and the Ni phase [01-1] zone pattern, respectively. In the other hand, Fig. 11(b) shows the highresolution TEM micrographs illustrating the atomic structures near the interface between intragranular $\mathrm{Ni} / \mathrm{Cu}$ grains. The HRTEM micrograph appears a tilted interface of which only one or two layers of atoms are randomly arranged. The interface is as thin as $2-3 \mathrm{~nm}$ and depicts a non-coherent character. This layer has an average thickness of 2 to 3 atomic planes, and is uniform along the boundary. There is no glassy or intermediate phase at the $\mathrm{NC} / \mathrm{BT}$ interface during the sort of sintering condition. Most of the observed interfaces of the NC/BT belong to incoherent junction. Furthermore, the BT layer exhibited a lattice structure with a spacing of $6.3 \AA$ and the lattice plane aligned along the 101 axis.

\section{Conclusion}

The shrinkage behavior and microstructure development of $\mathrm{Ni} / \mathrm{Cu}$ electrode with $\mathrm{BaTiO}_{3}$ particulates has been investigated. The results indicate several abnormal changes of the dilatometric curves. The linear shrinkage for the NBC composite experienced the reduction of $\mathrm{Cu}$-oxide from 200 to $450^{\circ} \mathrm{C}$. Besides, the first volume expansion of the NBC composite from 450 to $700^{\circ} \mathrm{C}$ was resulted from the evaporation of carbonaceous impurity in the $\mathrm{Cu}$ powder. Sintering shrinkage started either above $800^{\circ} \mathrm{C}$ for the case without $\mathrm{Cu}$ addition, or induced volume expansion above $1080^{\circ} \mathrm{C}$ due to the melting of $\mathrm{Cu}$ or alloying effect in $\mathrm{Ni} / \mathrm{Cu}$ alloy.

Furthermore, 30 to $50 \% \mathrm{Cu}$ addition into N15B exhibited excellent densification and wetting behavior in the $\mathrm{Ni} / \mathrm{Cu}$ electrode comparing to the pure $\mathrm{Ni}$ electrode. Good interfacial stability between BT particles and metallic electrode were obtained in the $\mathrm{Ni} / \mathrm{Cu}$ electrode. Besides, differential sintering behavior between pure $\mathrm{Ni}$ and $\mathrm{BaTiO}_{3}$ ceramics could be reduced by the addition of $\mathrm{Cu}$ as the $\mathrm{BT}$ amount of 5 to 20 mass\% in Ni electrode.

The studies of SEM/EDS and AES revealed that there was almost no inter-diffusion or reaction between the $\mathrm{Ni} / \mathrm{Cu}$ and pure $\mathrm{Ni}$ electrodes with $\mathrm{BaTiO}_{3}$ 
dielectric layer. Most importantly, the interface between $\mathrm{BaTiO}_{3}$ and $\mathrm{Ni} / \mathrm{Cu}$ (or pure $\mathrm{Ni}$ ) was very clean. The interfaces between $\mathrm{BaTiO}_{3}$ and $\mathrm{Ni} / \mathrm{Cu}$ boundary are incoherent. No defects and no glassy phase could be found at the interface. The $\mathrm{Cu}$ does not only improve the continuity of Ni electrode layer, but also induce no interfacial reaction with BT ceramics.

\section{Acknowledgment}

The authors like to thank the kindly offer of some processing equipments by Phycomp Taiwan Ltd., and the funding given by National Science Council (NSC922212-E002-097) in Taiwan.

\section{References}

1. J. Yamamatsu, N. Kawano, and T. Arashi, J. Power Source, 60, 199 (1996)

2. H. Saito, H. Chazono, H. Kishi, and N. Yamaoka, Jpn. J. Appl. Phys., 30, 2307 (1991).

3. G. With, J. Europ. Ceram. Soc., 12, 323 (1993).

4. Y. Park, Y.H. Kim, and H.G. Kim, Mater. Lett., 28, 101 (1996).

5. S. Sato, Y. Nakano, A. Sato, and T. Nomura, J. Europ. Ceram. Soc., 19, 1061 (1999).
6. L. Paulsen and E.K. Reed, Microelectr. Reliab., 42, 815 (2002).

7. Y. Masuda, T. Koumura, T. Okawa, and K. Koumoto, J. Colloid Interf. Sci., 26, 190 (2003).

8. S. F. Wang, J. Am. Ceram. Soc., 76(2), 474 (1993).

9. Y.I. Shin, K.M. Kang, Y.G. Jung, J.G. Yeo, S.G. Lee, and U. Paik, J. Europ. Ceram. Soc., 23, 1427 (2003).

10. R. Zuo, L. Li, and Z. Gui, Mat. Chem. Phys., 74, 182 (2002).

11. R.R. Tummala, J. Am. Ceram. Soc., 74, 895 (1991).

12. S.G. Lee, U. Paik, Y.I. Shin, J.W. Kim, and Y.G. Jung, Mater. Design., 24, 169 (2003).

13. G.W. Howatt, R.G. Breckenridge, and J.M. Brownlow, J. Am. Ceram. Soc., 30, 237 (1947).

14. R.E. Mistler, Am. Ceram. Soc. Bull., Oct., 82 (1998).

15. R. Chen, X. Wang, L. Li, and Z. Gui, Mater. Sci. Eng., B99, 298 (2003).

16. H. Hyuga, Y. Hayashi, T. Sekino, and K. Niihara, Nanostruct. Mater, 9, 547 (1997).

17. H. Emoto and J. Hojo, J. Ceram. Soc. Jpn., 100, 553 (1992).

18. W.D. Callister, Materials Science and Engineering An Introduction, 3rd ed., 1994

19. D.F.K. Hennings, J. Europ. Ceram. Soc., 21, 1637 (2001).

20. D.R. Lide, CRC Handbook of Chemistry and Physics, 72th ed., 1911 (1992).

21. D.A. Richard and R. Layland, Polyhedron, 16(12), 2105 (1997).

22. K.M. Kang, Y.G. Jung, U. Paik, and J.H. Kim, Mater. Res. Bull., 38, 555 (2003).

23. J.P. Bonsack, Am. Cream. Soc. Bull., 50, 488 (1971).

24. H.J. Hagemann and D. Hannings, J. Am. Ceram. Soc., 64, 590 (1981).

25. O. Parkash, H.S. Tewari, L. Pandey, R. Kumar, and D. Kumar, J. Am. Ceram. Soc., 72, 1520 (1989). 